\title{
Desenvolvimento vegetativo do noni (Morindacitrifolia L.) sob diferentes sistemas e lâminas de irrigação
}

VASCONCELOS,R.S'.,MIRANDA,F.R²., SOUSA,J.A².

Universidade Federal Rural de Pernambuco - UFRPE, Rua Dom Manoel de Medeiros, s/n, Dois Irmãos - CEP: 52171-900, Recife/PE; e-mail:rochelly17@hotmail.com; 'Embrapa Agroindústria Tropical, Rua Dra. Sara Mesquita, 2270 - CEP :60511-110,Fortaleza-CE;e-mail:fabio.miranda@embrapa.br;joão.alencar@embrapa.br

RESUMO: O noni é uma cultura de origem asiática que vem despertando interesse de agricultores brasileiros em virtude de suas propriedades fitoterápicas na medicina popular e de seu elevado valor comercial; contudo, são escassas as informações quanto ao manejo da cultura em geral e inexistentes estudos a respeito da irrigação da cultura no Brasil. Objetivou-se com este estudo definir, entre dois sistemas de irrigação e cinco laminas d'água, qual a melhor condição para o desenvolvimento vegetativo da cultura. O experimento foi realizado no período de maio de 2009 a março de 2010, em Trairi-CE. Utilizou-se o delineamento experimental de blocos casualizados e dois sistemas de irrigação localizada (gotejamento e microaspersão) dispostos em faixas verticais. Dentro de cada faixa foram distribuídos os blocos com as parcelas dos cincos níveis de irrigação correspondentes à aplicação de frações da evapotranspiração de referência FAO (ETo) de 40\%, 60\%, 80\% 100\% e 120\%. Para o sistema de irrigação por microaspersão as lâminas correspondentes foram: 109,3 mm, 135,8 mm, 187,9 mm, 227,8 $\mathrm{mm}$ e $297,7 \mathrm{~mm}$ e para sistema de irrigação por gotejamento: $83,4 \mathrm{~mm}, 1237 \mathrm{~mm}, 166,5 \mathrm{~mm}$, $204,7 \mathrm{~mm}$ e $254,4 \mathrm{~mm}$, respectivamente. Foram utilizadas cinco repetições. O desenvolvimento vegetativo de plantas de noni foi influenciado tanto pelos sistemas de irrigação, quanto pelas lâminas d'água aplicadas. A lâmina de irrigação equivalente a $227,8 \mathrm{~mm}$, correspondente a $100 \%$ da ETo, na irrigação por microaspersão, proporcionou maiores ganhos de diâmetro do coleto, altura da planta, e diâmetro de copa.

Palavras-chave: Morinda citrifolia L, Irrigação localizada, Manejo de irrigação.

\begin{abstract}
Vegetative development of noni (Morinda citrifolia L.) under different irrigation systems and water depths. Noni is a crop of Asian origin that has piqued the interest of Brazilian farmers because of its properties in herbal folk medicine and its high commercial value. However, there is little information about the crop management in general, and particularly on the irrigation of the crop in Brazil. The objective of this study was to define what localized irrigation system (drip or micro sprinklers) and water depth that provide the best vegetative growth of noni plants. The experiment was conducted from May 2009 to March 2010 in the city of Trairi, Brazil. We used a split block experimental design, with two irrigation systems (drip and micro sprinklers) arranged in vertical lines. Within each line, five irrigation levels, corresponding to the application of fractions of the reference evapotranspiration (ETo) $40 \% 60 \% 80 \% 100 \%$ and $120 \%$, were distributed in five blocks. For the micro sprinkler irrigation system, the corresponding slides were: $109.3 \mathrm{~mm}, 135.8 \mathrm{~mm}, 187.9 \mathrm{~mm}, 227.8 \mathrm{~mm}$ and $297.7 \mathrm{~mm}$, respectively, and for the drip irrigation system, they were: $83.4 \mathrm{~mm}, 123.7 \mathrm{~mm}, 166.5 \mathrm{~mm}, 204.7 \mathrm{~mm}$ and $254.4 \mathrm{~mm}$, respectively. The noni vegetative growth was influenced both by the irrigation systems and the depths of irrigation applied. The application of irrigation depths equivalent to $227.8 \mathrm{~mm}$, which corresponds to $100 \%$ of ETo with the use of micro sprinklers, provided the largest gains in stem diameter, plant height and canopy diameter.
\end{abstract}

Keywords: Morinda citrifolia L, Micro irrigation, Irrigation management. 


\section{INTRODUÇÃO}

As plantas medicinais vêm sendo utilizadas com finalidades terapêuticas há milhares de anos. Desde os primórdios da humanidade, o homem se utiliza das propriedades medicinais das plantas no combate as doenças.

A partir da década de 1980, foram desenvolvidos novos métodos de isolamento de substâncias ativas, tornando-se possível identificar substâncias em amostras complexas, tais como os extratos vegetais. Desta maneira, ressurgiu o interesse por compostos de origem vegetal que pudessem ser utilizados como protótipos para o desenvolvimento de novos fármacos (Turolla \& Nascimento, 2006).

O noni (Morinda citrifolia Linn) é uma planta pertencente à família Rubiaceae, originária do sudoeste da Ásia, e, subsequentemente, foi distribuída através de vários colonizadores pelas ilhas do pacífico (Whistler, 1991, citado por McClathey, 2002). É uma planta medicinal popular e tradicional que tem sido usada por mais de 2000 anos pelos povos polinésios. Atualmente, o noni é encontrado em várias partes do mundo, tais como nas regiões tropicais da África (centro e sul), no Caribe, Austrália, China, Malásia, Indonésia, Índia (Lübeck\& Hannes, 2001), na América do Norte e América do Sul (Ross, 2001).

O emprego tradicional pelos polinésios é devido aos efeitos medicinais atribuídos ao noni relacionados com atividade antibacteriana, antiviral, antifúngica, antitumoral, anti-helmíntica, analgésica, antiinflamatória, hipotensora e imunoestimulante, sendo usado há mais de 2000 anos. Segundo Wang et al. (2002), o suco de noni ganhou espaço na medicina alternativa devido a seus prováveis efeitos antioxidantes e antiinflamatórios, no combate de diferentes tipos de doenças como câncer, aterosclerose, diabetes, entre outras. Entretanto, as evidências científicas para os benefícios do suco dessa fruta ainda são limitadas.

Apesar da demanda internacional pelos produtos oriundos do noni, principalmente o suco dos frutos, no Brasil é bastante recente a tentativa de cultivo do noni, o qual é realizado empiricamente por pessoas que trouxeram algumas sementes do Caribe ou da Polinésia e se tornaram vendedores de sementes e mudas pela Internet. No Brasil, existem relatos de plantios no Acre, São Paulo, Pará, Sergipe e Ceará, entre outros estados. Contudo, ainda são poucos os trabalhos de pesquisa desenvolvidos no Brasil com essa espécie e inexistentes trabalhos com lâminas de irrigação. Não se conhece ainda a necessidade hídrica dessa cultura para as condições climáticas do estado do Ceará, tornandose necessário seu estudo.

Objetivou-se com o presente estudo definir o sistema de irrigação localizado (gotejamento ou microaspersão) e a lâmina de irrigação que proporciona o melhor desenvolvimento vegetativo da cultura do noni.

\section{MATERIAL E MÉTODO}

O experimento foi realizado no período de maio de 2009 a março de 2010 em uma área experimental localizada na Fazenda Alberto Antônio (latitude $3^{\circ} 16^{\prime} 40^{\prime \prime S}$, longitude $39^{\circ} 16^{\prime} 08^{\prime \prime} \mathrm{O}$, altitude $18 \mathrm{~m}$ ), localizada em Trairi-CE.

O clima da região, pela classificação de Köppen é do tipo Aw', sendo Tropical quente, com média anual de precipitação pluviométricade 1.321 $\mathrm{mm}$, concentrados entre fevereiro e maio. O solo da área foi classificado como Argissolo Amarelo Distrocoeso Típico.

Utilizou-se o delineamento experimental em faixas com blocos casualizados (splitblock), com dois sistemas de irrigação localizada (gotejamento e microaspersão) dispostos em faixas verticais. Dentro de cada faixa foram distribuídos os blocos com as parcelas dos cincos níveis de irrigação, correspondentes à aplicação de frações da evapotranspiração de referência FAO (ETo) de $40 \%, 60 \%, 80 \% 100 \%$ e $120 \%$. Foram utilizadas cinco repetições. Cada parcela experimental foi constituida por seis plantas de uma mesma fileira, sendo consideradas úteis as quatro plantas centrais de cada parcela.

No preparo da área foi realizada aração e abertura de covas de $0,4 \mathrm{~m} \times 0,4 \mathrm{~m} \times 0,4 \mathrm{~m}$, no espaçamento de $5 \mathrm{~m} \times 3 \mathrm{~m}$. Na adubação de plantio foram utilizados $5 \mathrm{~L}$ de esterco bovino , 0,5 L de cinza e $1 \mathrm{~kg}$ de fosfato natural por cova.

O transplantio foi realizado em 05/05/2009, utilizando mudas com seis a oito pares de folhas definitivas ( 75 dias após a semeadura) e a aplicação dos tratamentos foi iniciada após o fim da estação chuvosa, em julho/2009, aos 83 dias após o transplantio (DAT).

A adubação de cobertura foi realizada em maio de 2009, manualmente, em sulcos rasos com profundidade de $5 \mathrm{~cm}$, em forma de circulo sob a projeção da copa. Foram aplicados $10 \mathrm{~L}$ de composto orgânico (matéria orgânica $=462,3 \mathrm{~g}$ $\mathrm{kg}^{-1}$ (base seca); $\mathrm{N}$ total $=39,26 \mathrm{~g} \mathrm{~kg}^{-1}$ (composto seco); P-total $=3,29 \mathrm{~g} \mathrm{~kg}^{-1}$ (composto seco); K-total $=8,57 \mathrm{~g} \mathrm{~kg}^{-1}$ (composto seco); Ca-total $=48,29 \mathrm{~g} \mathrm{~kg}^{-1}$ (composto seco); Mg-total 212,64 $\mathrm{g} \mathrm{kg}^{-1}$ (composto seco); Na-total = 2,66 g kg-1 (composto seco); Cutotal $=74,0 \mathrm{mg} \mathrm{kg}^{-1}$ (composto seco); Fe-total = $26730 \mathrm{mg} \mathrm{kg}^{-1}$ (composto seco); Zn-total $=183,0$ $\mathrm{mg} \mathrm{kg}^{-1}$ (composto seco); Mn-total $=443,0 \mathrm{mg}$ $\mathrm{kg}^{-1}$ (composto seco). A área foi mantida livre de

Rev. Bras. PI. Med., Campinas, v.16, n.2, supl. I, p.388-397, 2014. 
plantas daninhas por meio de capinas manuais até aproximadamente 1,0 metro em torno das plantas e por meio de roçagem mecânica nas entrelinhas.

Nas parcelas do sistema de gotejamento foram utilizados gotejadores autocompensadores de pressão da marca Plastro, modelo Katif, com vazões nominais de 2,3 e 3,7 L h ${ }^{-1}$ e pressão de serviço de $150 \mathrm{kPa}$. Para cada planta foi instalado gotejadores em dois pontos da linha lateral situados a $0,3 \mathrm{~m}$ das plantas. O número e a combinação de gotejadores por planta variou de acordo com a vazão necessária para a aplicação das lâminas de irrigação em cada tratamento. Foram utilizadas vazões nominais por planta de 4,$6 ; 7,4 ; 9,7 ; 12,0$ e 14,8 $\mathrm{L} \mathrm{h}^{-1}$, nos tratamentos de $40 \%, 60 \%, 80 \% 100 \%$ e $120 \%$ da ETo, respectivamente. $\mathrm{O}$ diâmetro molhado médio dos gotejadores, medido no campo, foi de $0,47 \mathrm{~m}$.

Nas parcelas irrigadas por microaspersão foram utilizados microaspersores rotativos autocompensantes (um emissor por planta), marca Plastro, modelo Rondo RFR. Para a diferenciação dos tratamentos de irrigação foram utilizados microaspersores com vazões nominais de 20,30 , 41,53 e $70 \mathrm{~L} \mathrm{~h}^{-1}$, nos tratamentos $40 \%, 60 \%, 80 \%$ $100 \%$ e $120 \%$ da ETo, respectivamente. Para reduzir e padronizar o diâmetro molhado dos emissores foram utilizados limitadores de distribuição de água acoplados na bailarina dos microaspersores. Com esse dispositivo o diâmetro molhado médio dos microaspersores medido no local foi de $1,0 \mathrm{~m}$.

No inicio das irrigações foram determinadas os coeficientes de uniformidade de distribuição (CUD) de água dos dois sistemas de irrigação, utilizando-se a metodologia proposta por Keller e Karmeli (1975). Os valores de CUD medidos foram de $91,5 \%$ e $89,2 \%$ nos sistemas de gotejamento e microaspersão, respectivamente.

As irrigações foram realizadas com turno de rega de dois dias nos meses de julho a setembro/2009 e, diariamente, nos meses de outubro/2009 a novembro/2010. O tempo de irrigação foi calculado de acordo com a equação:

$$
T i=\frac{T R \times F \times E T_{o} \times E_{L} \times E_{e} \times F_{C}}{E_{i} \times q_{e}}
$$

Em que: Ti é o tempo de irrigação, em horas; TR é o turno de rega, em dias; F é o fator correspondente ao tratamento de irrigação (decimal); ETo é a evapotranspiração de referência média mensal, em $\mathrm{mm}$ dia $^{-1} ; E_{L}$ é o espaçamento entre linhas de irrigação, em $\mathrm{m} ; \mathrm{E}_{\mathrm{e}}$ é o espaçamento entre emissores, em $m ; F_{c}$, é o fator de cobertura do solo, adimensional; Ei é a eficiência de irrigação, adimensional e $\mathrm{q}_{\mathrm{e}}$ é a vazão do emissor, em $\mathrm{L} \mathrm{h}^{-1}$.

A evapotranspiração utilizada para o calculo do tempo de irrigação foram utilizados valores médios mensais da região, calculados pelo método de Penman-Monteith disponibilizados por Cabral (2000).

A água utilizada na irrigação foi obtida de um poço tipo amazonas. De acordo com a análise química, a água foi classificada como C3S1 segundo a classificação do USDA, com alta salinidade e baixo conteúdo de sódio (Condutividade elétrica $\left.=0,81 \mathrm{dS} \mathrm{m}^{-1}, \mathrm{RAS}=10,28\right)$. Os volumes de água aplicados nos tratamentos foram medidos utilizando hidrômetros instalados nos cabeçais de controle de cada sistema de irrigação. No sistema de irrigação por microaspersão as lâminas foram: $109,3 \mathrm{~mm}$, $135,8 \mathrm{~mm}, 187,9 \mathrm{~mm}, 227,8 \mathrm{~mm}$ e $297,7 \mathrm{~mm}$ correspondentes aos tratamentos de $40 \%, 60 \%, 80 \%$ $100 \%$ e $120 \%$ da evapotranspiração de referência (Eto), e no siterma de irrigação por gotejamento foram: 83,4 mm, $1237 \mathrm{~mm}, 166,5 \mathrm{~mm}, 204,7 \mathrm{~mm}$ e $254,4 \mathrm{~mm}$, respectivamente. As lâminas entre os sistemas variaram em função do fator de cobertura do solo ( $F c$ ), que foram utilizados inicialmente em função do bulbo molhado do gotejador e do microaspersor enquanto o fator de cobertura da planta era menor que este. Um pluviômetro foi utilizado para monitorar as precipitações pluviométricas na área experimental. Foram avaliados em todas as plantas úteis os seguintes parâmetros de desenvolvimento vegetativo: altura da planta, diâmetro do coleto e diâmetro de copa. A altura e o diâmetro de copa foram medidos com o auxilio de uma fita métrica. $O$ diâmetro do coleto foi medido a uma altura de $0,1 \mathrm{~m}$ da superfície do solo, com um paquímetro digital (precisão de 0,05 mm).

Foram realizadas quatro avaliações de desenvolvimento nas seguintes datas: 16/07/2009 (72 dias após o plantio, DAP), 30/09/09 (148 DAP), 18/12/2009 (227 DAP) e 16/03/2010 (315 DAP). Para a variável diâmetro de copa foram realizadas somente três avaliações nas seguintes datas: 30/09/09 (148 DAP), 18/12/2009 (227 DAT) e 16/03/2010 (315 DAP). Os dados foram submetidos à análise de variância e ao teste de médias (Tukey), utilizando o programa SAS-Statistical Analysis Software.

\section{RESULTADO E DISCUSSÃO}

\section{Irrigação}

Nos tratamentos com irrigação por microaspersão as lâminas de irrigação aplicadas foram em média $14 \%$ maiores que nos tratamentos de gotejamento (Figuras 1 e 2), isso ocorreu em virtude do fator de molhamento do sistema de microaspersão ser maior que o fator de cobertura do solo da cultura e maior que o fator de molhamento do sistema de irrigação por gotejamento até o mês

Rev. Bras. PI. Med., Campinas, v.16, n.2, supl. I, p.388-397, 2014. 
de novembro/2009. A partir de dezembro/2009 o fator de cobertura do solo passou a ser maior que os fatores de molhamento de ambos os sistemas, sendo então utilizado para o cálculo das lâminas de irrigação dos dois sistemas de irrigação, que se tornaram bastantes próximas em termos de $\mathrm{mm}$ mês-1.

\section{Crescimento vegetativo Diâmetro do coleto}

$\mathrm{Na}$ avaliação realizada aos 148 DAT (65 dias após o início da aplicação dos tratamentos) foram observadas diferenças significativas $(p<0,01)$ no diâmetro do coleto das plantas apenas entre os sistemas de irrigação (Tabela 1). O sistema de irrigação por microaspersão apresentou maior diâmetro de coleto em relação ao sistema de gotejamento (Tabela 2).

Após 144 dias do início da aplicação dos tratamentos (227 DAT) e ainda na estação seca, foram observadas diferenças significativas entre os sistemas de irrigação $(p<0,01)$ e entre as lâminas de água aplicadas $(p<0,05)$. Plantas irrigadas por microaspersão apresentaram maior diâmetro de coleto em relação aquelas irrigadas por gotejamento. Houve diferença significativa das lâminas de $40 \%$ e $60 \%$ ETo com as lâminas de $100 \%$ e $120 \%$ da ETo, obtendo- se um aumento do diâmetro do coleto da menor lâmina para maior (Tabela 3).

$\mathrm{Na}$ avaliação realizada aos 315 DAT (durante a estação chuvosa) não houve diferenças significativas entre os sistemas de irrigação, nem entre as lâminas de água aplicadas. Isso provavelmente ocorreu em virtude da uniformidade

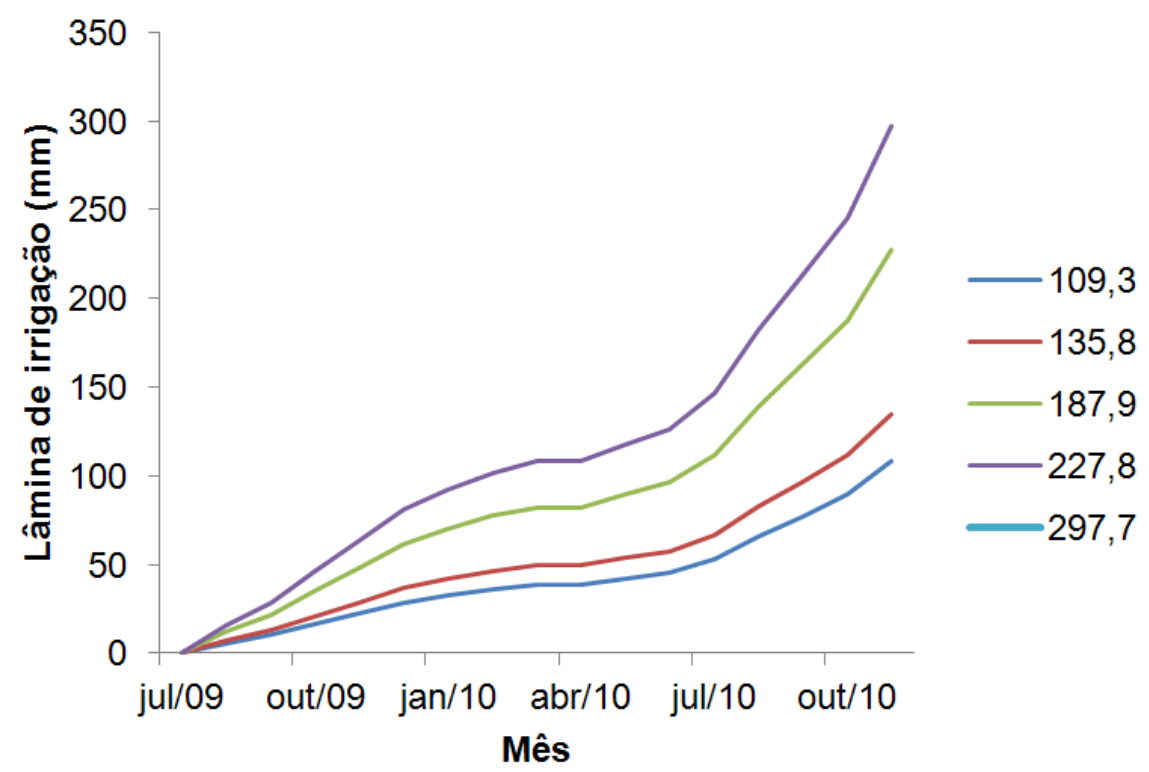

FIGURA 1. Lâminas de irrigação acumuladas aplicadas nos tratamentos de microaspersão. Trairi-CE, 2009/2010.

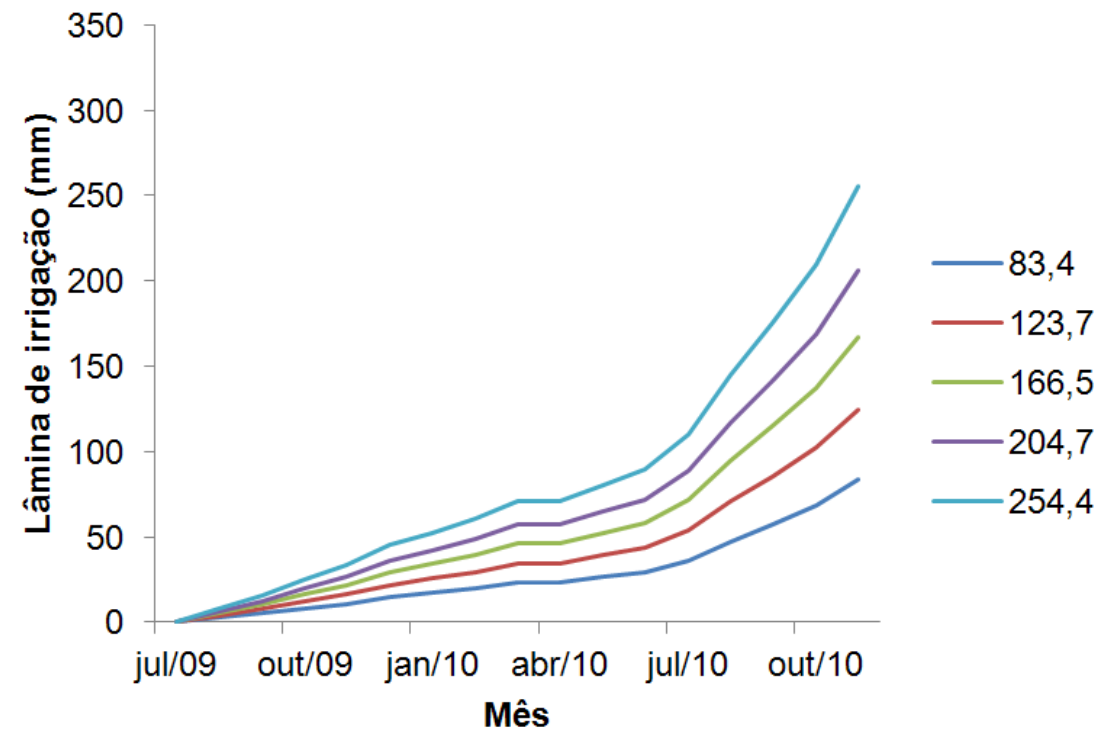

FIGURA 2. Lâminas de irrigação acumuladas aplicadas nos tratamentos de gotejamento. Trairi-CE, 2009/2010.

Rev. Bras. PI. Med., Campinas, v.16, n.2, supl. I, p.388-397, 2014. 
de disponibilidade de água em todos os tratamentos, proveniente das precipitações da ordem de 164 $\mathrm{mm}$, que ocorreram nos 90 dias que antecederam a avaliação.

As variações de diâmetro do coleto, em função das lâminas de irrigação aplicadas até os 227 DAT, nos tratamentos de sistemas de irrigação por microaspersão e gotejamento, são apresentadas nas Figuras 1 e 2, respectivamente. Nota-se que o diâmetro do coleto aumentou de forma linear com o aumento da lâmina de irrigação em ambos os sistemas de irrigação, contudo, o aumento foi mais acentuado (maior coeficiente angular) nas plantas irrigadas por gotejamento. Em geral, plantas com maior diâmetro apresentam melhores condições de sobrevivência por apresentarem maior capacidade de formação e crescimento de raízes novas (Reis et al.,1991).

\section{Altura da planta}

Para a variável altura da planta foram observadas diferenças significativas $(p<0,01)$ entre os sistemas de irrigação nas avaliações realizadas aos 148 e 227 DAT (Tabela 4). Entre as lâminas de irrigação, foram observadas diferenças significativas apenas na avaliação realizada aos

TABELA1. Resumo da análise de variância para a variável diâmetro do coleto nas avaliações de 148, 227 e 315 DAT. Trairi-CE, 2009-2010

\begin{tabular}{lcccc}
\hline \multirow{2}{*}{ Fontes de variação } & \multirow{2}{*}{$\mathrm{GL}$} & \multicolumn{3}{c}{ Quadrados Médios } \\
\cline { 3 - 5 } & & 148 DAT & 227 DAT & 315 DAT \\
\hline Bloco & 4 & $11,12^{*}$ & $20,11^{*}$ & 10,41 ns \\
Sistema de irrigação (A) & 1 & $217,98^{* *}$ & $270,04^{* *}$ & 91,82 ns \\
Resíduo (A) & 4 & 0,27 & 1,05 & 22,38 \\
Lâmina (B) & 4 & 4,31 ns & $31,87^{*}$ & 24,87 ns \\
Resíduo (B) & 16 & 3,44 & 5,23 & 13,98 \\
Interação (A x B) & 4 & $3,59^{\text {ns }}$ & 1,10 ns & $20,86^{\text {ns }}$ \\
Resíduo (A x B) & 16 & 3,59 & 4,93 & 14,96 \\
TOTAL & & 8,32 & 13,25 & 17,74 \\
\hline
\end{tabular}

** significativo ao nível de $1 \%$ de probabilidade, ${ }^{*}$ significativo ao nível de $5 \%$ de probabilidade, ns não significativo.

TABELA2. Médias do diâmetro do coleto de plantas de noni irrigadas por gotejamento e por microaspersão nas avaliações realizadas aos 148, 227 e 315 DAT. Trairi-CE, 2009-2010

\begin{tabular}{lllll}
\hline \multicolumn{5}{c}{ Diâmetro do coleto $(\mathrm{mm})$} \\
\hline Variáveis & $148 \mathrm{DAT}$ & 227 DAT & 315 DAT & Médias \\
Microaspersão & $24,92 \mathrm{a}$ & $31,06 \mathrm{a}$ & $39,83 \mathrm{a}$ & 27,89 \\
Gotejamento & $20,75 \mathrm{~b}$ & $26,41 \mathrm{~b}$ & $37,12 \mathrm{a}$ & 24,78 \\
\hline
\end{tabular}

Médias seguidas de letras iguais na vertical não diferem entre si pelo teste de Tukey a $5 \%$.

TABELA3. Médias do diâmetro do coleto de plantas de noni irrigadas por gotejamento e por microaspersão nas avaliações realizadas aos 148, 227 e 315 DAT. Trairi-CE, 2009-2010

\begin{tabular}{lllll}
\hline \multicolumn{5}{l}{ Diâmetro do coleto $(\mathrm{mm})$} \\
\hline Tratamentos & $148 \mathrm{DAT}$ & 227 DAT & 315 DAT & Médias \\
$40 \%$ ETo & $22,14 \mathrm{a}$ & $26,51 \mathrm{c}$ & $36,99 \mathrm{a}$ & 25,31 \\
$60 \%$ ETo & $22,15 \mathrm{a}$ & $27,32 \mathrm{bc}$ & $37,88 \mathrm{a}$ & 25,64 \\
$80 \%$ ETo & $23,28 \mathrm{a}$ & $29,08 \mathrm{ab}$ & $37,28 \mathrm{a}$ & 26,25 \\
$100 \%$ ETo & $23,01 \mathrm{a}$ & $30,02 \mathrm{a}$ & $40,69 \mathrm{a}$ & 27,23 \\
$120 \%$ ETo & $23,57 \mathrm{a}$ & $30,74 \mathrm{a}$ & $39,51 \mathrm{a}$ & 27,24 \\
Médias & 22,83 & 28,73 & 38,47 & 26,33 \\
\hline
\end{tabular}

Médias seguidas de letras iguais na vertical não diferem entre si pelo teste de Tukey a 5\%.

Rev. Bras. PI. Med., Campinas, v.16, n.2, supl. I, p.388-397, 2014. 


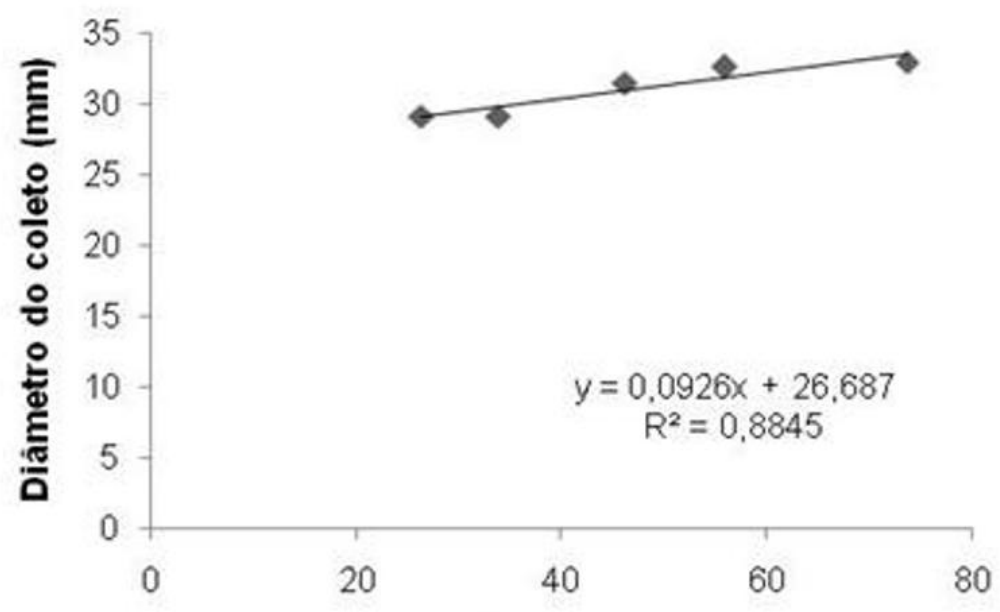

Lảmina de irrigação $(\mathrm{mm})$

FIGURA1. Variação do diâmetro do coleto de plantas de noni em função de diferentes lâminas de irrigação aplicadas por microaspersão até 227 DAT. Trairi-CE, 2009.

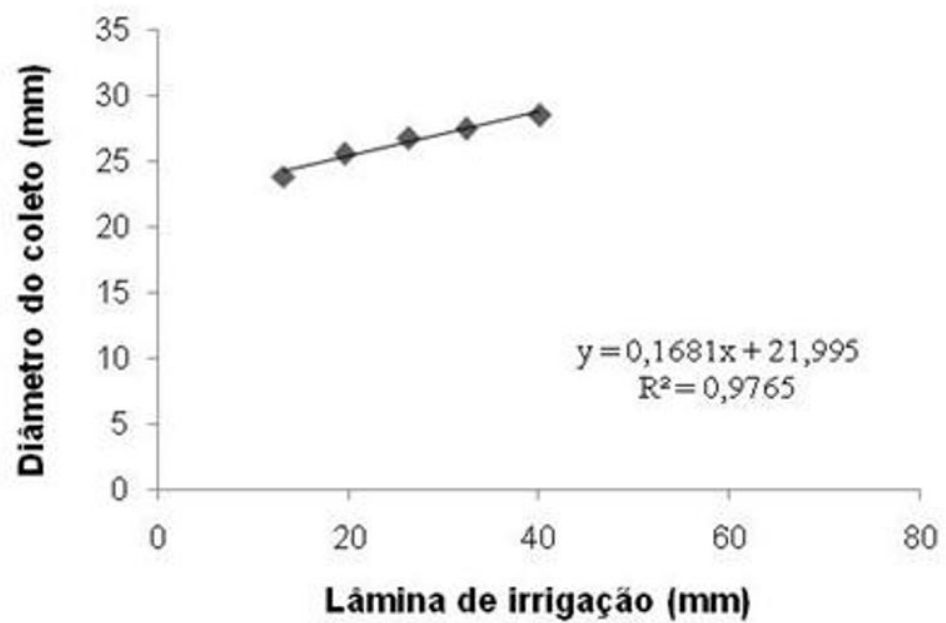

FIGURA 2. Variação do diâmetro do coleto de plantas de noni em função de diferentes lâminas de irrigação aplicadas por gotejamento até 227 DAT. Trairi-CE, 2009.

227 DAT $(p<0,01)$.

Aos 148 e 227 DAT as plantas irrigadas por microaspersão apresentaram maiores médias de altura em relação às plantas irrigadas por gotejamento (Tabela 5). Tal diferença, provavelmente ocorreu em virtude das maiores lâminas de água aplicadas e maiores áreas molhadas nas parcelas irrigadas por microaspersão em relação as parcelas com gotejamento no período que antecedeu às avaliações (julho-novembro/2009).

Aos 227 DAT não houve diferença significativa de altura da planta entre os níveis de irrigação de 100 e $120 \%$ da ETo. No entanto, esses dois tratamentos apresentaram médias de altura de plantas estatisticamente superiores aos demais tratamentos (Tabela 6).

Nas Figuras 3 e 4 são apresentados os gráficos com as variações da altura de plantas em função das lâminas de irrigação aplicadas até os 227 DAT, nos tratamentos de sistemas de irrigação por microaspersão e gotejamento, respectivamente. Nota-se que houve aumento da altura da planta à medida que aumentaram as lâminas de irrigação em ambos os sistemas.

Da mesma forma que no Diâmetro do Coleto, na Altura da Planta, houvemaumentu de forma linear com o aumento da lâmina de irrigação em ambos os sistemas de irrigação, todavia, o aumento foi mais acentuado no sistema de irrigação por gotejamento.

\section{Diâmetro de copa}

$\mathrm{Na}$ avaliação realizada aos 148 DAT foram observadas diferenças significativas $(p<0,01)$ com relação ao diâmetro de copa apenas entre os tratamentos de sistemas de irrigação (Tabela 
TABELA4. Resumo da análise de variância para a variável altura da planta nas avaliações realizadas aos 148 , 227 e 315 DAT. Trairi-CE, 2009-2010

\begin{tabular}{lcccc}
\hline \multirow{2}{*}{ Fontes de variação } & \multirow{2}{*}{ GL } & \multicolumn{3}{c}{ Quadrados Médios } \\
\cline { 3 - 5 } & & 148 DAT & 227 DAT & 315 DAT \\
\hline Bloco & 4 & $62,74^{* *}$ & $61,94^{*}$ & $49,22^{\text {ns }}$ \\
Sistema de irrigação (A) & 1 & $1366,59^{* *}$ & $2237,80^{* *}$ & 54,08 ns \\
Resíduo (A) & 4 & 0,73 & 5,75 & 58,03 \\
Lâmina (B) & 4 & 28,56 ns & $185,27^{* *}$ & $59,14^{\text {ns }}$ \\
Resíduo (B) & 16 & 11,27 & 17,06 & 51,55 \\
Interação (A x B) & 4 & $4,84^{\text {ns }}$ & $3,41^{\text {ns }}$ & $46,31^{\text {ns }}$ \\
Resíduo (A x B) & 16 & 11,90 & 16,08 & 41,08 \\
\hline TOTAL & & 43,37 & 77,09 & 48,72 \\
\hline
\end{tabular}

** significativo ao nível de $1 \%$ de probabilidade, ${ }^{*}$ significativo ao nível de $5 \%$ de probabilidade, ns não significativo.

TABELA5. Médias da altura de plantas de noni irrigadas por gotejamento e por microaspersão nas avaliações realizadas aos 148, 227 e 315 DAT. Trairi-CE, 2009-2010

\begin{tabular}{lcccc}
\hline \multicolumn{5}{c}{ Altura de plantas $(\mathrm{cm})$} \\
\hline Variáveis & 148 DAT & 227 DAT & 315 DAT & Médias \\
Microaspersão & $62,43 \mathrm{a}$ & $78,63 \mathrm{a}$ & $97,12 \mathrm{a}$ & 67,73 \\
Gotejamento & $51,98 \mathrm{~b}$ & $65,25 \mathrm{~b}$ & $95,04 \mathrm{a}$ & 63,69 \\
\hline
\end{tabular}

Médias seguidas de letras iguais na vertical não diferem entre si pelo teste de Tukey a $5 \%$.

TABELA6. Médias da variável altura de plantas de noni submetidas a diferentes lâminas de irrigação, nas avaliações realizadas aos 148, 227 e 315 DAT. Trairi-CE, 2009-2010

\begin{tabular}{ccccc}
\hline \multicolumn{5}{c}{ Altura de plantas $(\mathrm{cm})$} \\
\hline Tratamentos & 148 DAT & 227 DAT & 315 DAT & Médias \\
$40 \%$ ETo & $56,82 \mathrm{a}$ & $68,42 \mathrm{bc}$ & $93,82 \mathrm{a}$ & 50,21 \\
$60 \%$ ETo & $54,57 \mathrm{a}$ & $66,95 \mathrm{c}$ & $95,70 \mathrm{a}$ & 49,25 \\
$80 \%$ ETo & $57,57 \mathrm{a}$ & $71,87 \mathrm{~b}$ & $93,97 \mathrm{a}$ & 50,79 \\
$100 \%$ ETo & $57,94 \mathrm{a}$ & $75,97 \mathrm{a}$ & $99,62 \mathrm{a}$ & 53,01 \\
$120 \%$ ETo & $59,12 \mathrm{a}$ & $76,47 \mathrm{a}$ & $97,27 \mathrm{a}$ & 52,88 \\
\hline Médias & 57,20 & 71,93 & 96,08 & 51,23 \\
\hline
\end{tabular}

Médias seguidas de letras iguais na vertical não diferem entre si pelo teste de Tukey a $5 \%$.

7). Na avaliação realizada aos 227 DAT houve diferenças significativas $(p<0,01)$ tanto para os sistemas de irrigação, quanto para as lâminas de água aplicadas. Na avaliação realizada aos 315 DAT, não foram observadas diferenças significativas entre os tratamentos.

O sistema de irrigação por microaspersão apresentou maior diâmetro de copa em relação ao sistema de gotejamento nas avaliações de 148 DAT e 227 DAT (Tabela 8).

$\mathrm{Na}$ avaliação realizada aos 227 DAT as médias de diâmetro de copa do tratamento $120 \%$ da ETo foram significativamente maiores que as médias dos tratamentos 40, 60 e $80 \%$ ETo (Tabela 9). Houve uma tendência linear para aumento do diâmetro de copa em função do aumento da lâmina de irrigação aplicada em ambos os sistemas de irrigação (Figura 5 e 6). No entanto, o sistema de gotejamento apresentou aumento mais acentuado no diâmetro de copa em função do aumento na lâmina de irrigação.

De forma geral, observou-se que o sistema de irrigação por microaspersão apresentou melhores resultados que o sistema de irrigação por gotejamento em termos de desenvolvimento vegetativo das plantas de noni. Tal fato provavelmente está associado aos maiores valores de área molhada por planta e da lâmina de água aplicadam por microaspersão. Quanto aos níveis de irrigação, observou-se que à medida que passaram os meses de seca, aumentaram as diferenças no desenvolvimento das plantas em virtude das diferentes lâminas de água aplicadas, e que as aplicações de lâminas de irrigação equivalentes a $100 \%$ e $120 \%$ da ETo promoveram maior desenvolvimento vegetativo do noni. Durante o período chuvoso as diferenças entre

Rev. Bras. PI. Med., Campinas, v.16, n.2, supl. I, p.388-397, 2014. 


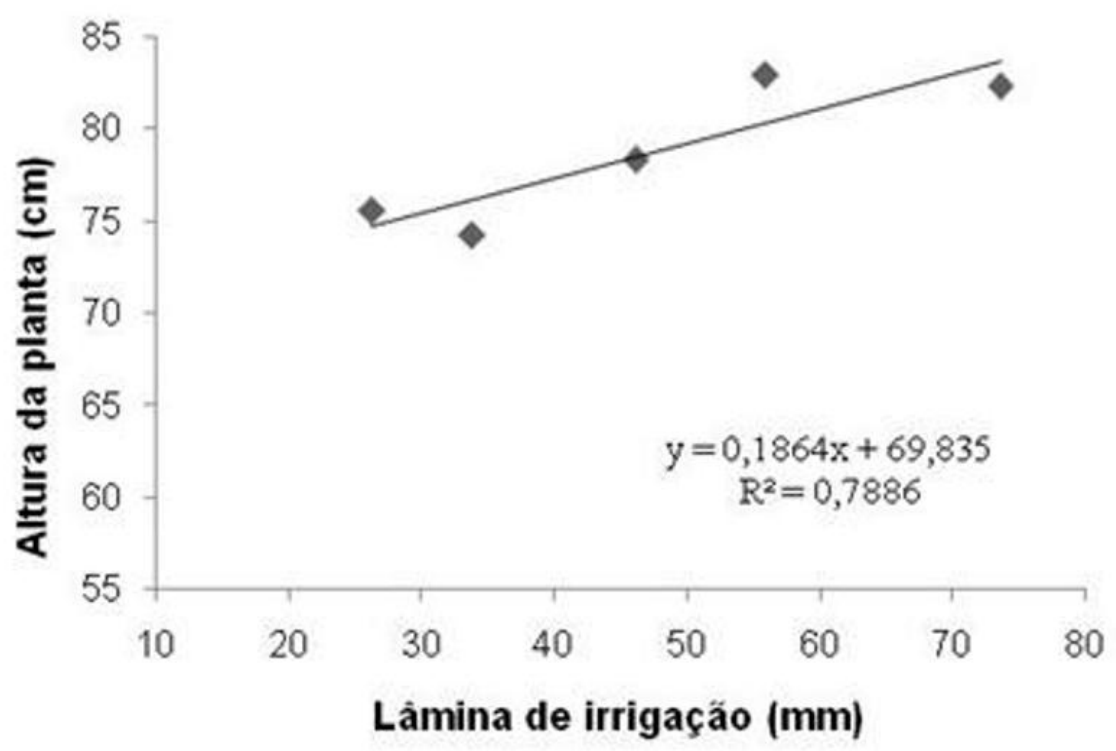

FIGURA 3. Variação da altura de plantas de noni em função de diferentes lâminas de irrigação aplicadas por microaspersão até 227 DAT. Trairi-CE, 2009.

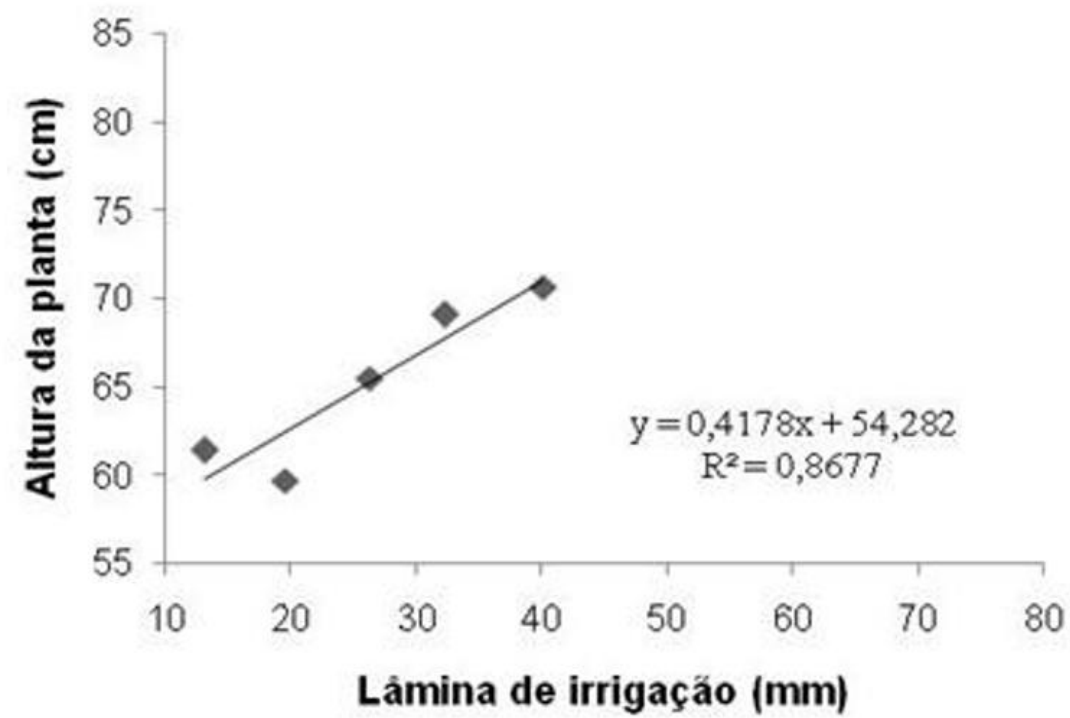

FIGURA 4. Variação da altura de plantas de noni em função de diferentes lâminas de irrigação aplicadas por gotejamento até 227 DAT. Trairi-CE, 2009.

TABELA7. Resumo da análise de variância para a variável diâmetro de copa nas avaliações realizadas aos 148, 227 e 315 DAT. Trairi-CE, 2009-2010

\begin{tabular}{lllll}
\hline \multirow{2}{*}{ Fontes de variação } & \multirow{2}{*}{ GL } & \multicolumn{3}{l}{ Quadrados Médios } \\
\cline { 3 - 5 } & & 148 DAT & 227 DAT & 315 DAT \\
\hline Bloco & 4 & 35,33 & $235,85^{* *}$ & $58,42^{\text {ns }}$ \\
Sistema de irrigação (A) & 1 & $506,38^{* *}$ & $888,23^{* *}$ & $5,51^{\text {ns }}$ \\
Resíduo (A) & 4 & 18,88 & 20,54 & 205,86 \\
Lâmina (B) & 4 & $50,91^{\text {ns }}$ & $560,92^{* *}$ & $255,50^{\text {ns }}$ \\
Resíduo (B) & 16 & 23,95 & 23,13 & 183,77 \\
Interação (Ax B) & 4 & 21,51 & $21,45^{\text {ns }}$ & $131,84^{\text {ns }}$ \\
Resíduo (A x B) & 16 & 13,25 & 19,64 & 99,92 \\
\hline TOTAL & & 32,82 & 100,57 & 145,94 \\
\hline
\end{tabular}

** significativo ao nível de $1 \%$ de probabilidade, ${ }^{*}$ significativo ao nível de $5 \%$ de probabilidade, ns não significativo.

Rev. Bras. PI. Med., Campinas, v.16, n.2, supl. I, p.388-397, 2014. 
TABELA8. Médias do diâmetro de copa de plantas de noni irrigadas por gotejamento e por microaspersão nas avaliações realizadas aos 148, 227 e 315 DAT. Trairi-CE, 2009-2010

\begin{tabular}{lllll}
\hline \multirow{2}{*}{ Variáveis } & \multicolumn{4}{l}{ Diâmetro de copa $(\mathrm{cm})$} \\
\cline { 2 - 5 } & 148 DAT & 227 DAT & 315 DAT & Médias \\
\hline Microaspersão & $66,09 \mathrm{a}$ & $79,15 \mathrm{a}$ & $107,61 \mathrm{a}$ & 84,28 \\
\hline Gotejamento & $59,72 \mathrm{~b}$ & $70,72 \mathrm{~b}$ & $106,95 \mathrm{a}$ & 79,13 \\
\hline
\end{tabular}

Médias seguidas de letras iguais na vertical não diferem entre si pelo teste de Tukey a $5 \%$.

TABELA 9. Médias da variável diâmetro de copa de plantas de noni submetidas a diferentes lâminas de irrigação nas avaliações realizadas aos 148, 227 e 315 DAT. Trairi-CE, 2009-2010

\begin{tabular}{lllll}
\hline \multirow{2}{*}{ Tratamentos } & \multicolumn{4}{l}{ Diâmetro de copa $(\mathrm{cm})$} \\
\cline { 2 - 5 } & 148 DAT & 227 DAT & 315 DAT & Médias \\
\hline $40 \%$ ETo & $60,69 \mathrm{a}$ & $65,94 \mathrm{c}$ & $101,95 \mathrm{a}$ & 76,19 \\
$60 \%$ ETo & $61,07 \mathrm{a}$ & $68,27 \mathrm{c}$ & $106,42 \mathrm{a}$ & 78,58 \\
$80 \%$ ETo & $65,51 \mathrm{a}$ & $77,78 \mathrm{~b}$ & $104,24 \mathrm{a}$ & 82,51 \\
$100 \%$ ETo & $62,17 \mathrm{a}$ & $79,27 \mathrm{ab}$ & $115,15 \mathrm{a}$ & 85,53 \\
$120 \%$ ETo & $65,09 \mathrm{a}$ & $83,42 \mathrm{a}$ & $108,65 \mathrm{a}$ & 85,72 \\
\hline Médias & 62,91 & 74,94 & 107,28 & 81,70 \\
\hline
\end{tabular}

Médias seguidas de letras iguais na vertical não diferem entre si pelo teste de Tukey a $5 \%$.

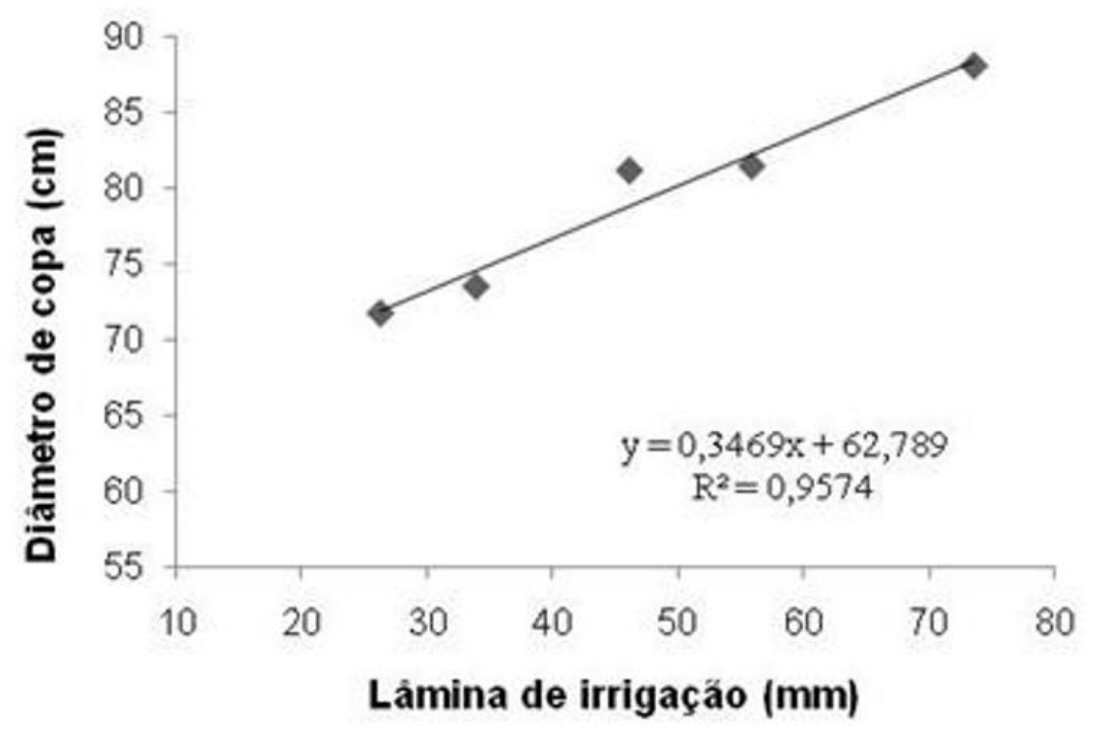

FIGURA 5. Variação do diâmetro de copa de plantas de noni submetidas a diferentes lâminas de irrigação aplicadas por microaspersão até 227 DAT. Trairi-CE, 2009.

os tratamentos de sistemas de irrigação e entre as lâminas tenderam a desaparecer.

Estudos realizados com outras espécies da mesma família do noni, como o café, apresentam resultados semelhantes. Arantes et al. (2006), avaliando o desenvolvimento do cafeeiro (Coffea arabica L.) sob irrigação, verificou que as características altura de planta e diâmetro de copa apresentaram aumento de comportamento linear à medida que se aumentou a lâmina de irrigação aplicada de $0 \%$ a $120 \%$ da evaporação do tanque classe A. Alves et al. (2000), avaliando o crescimento do cafeeiro sob diferentes lâminas de irrigação, verificou que o maior crescimento da cultura ocorreu com a reposição de $100 \%$ da evaporação do tanque classe $A$, o que, nas condições do experimento, correspondia a $133 \%$ ETo.

\section{CONCLUSÃO}

O desenvolvimento vegetativo de plantas 


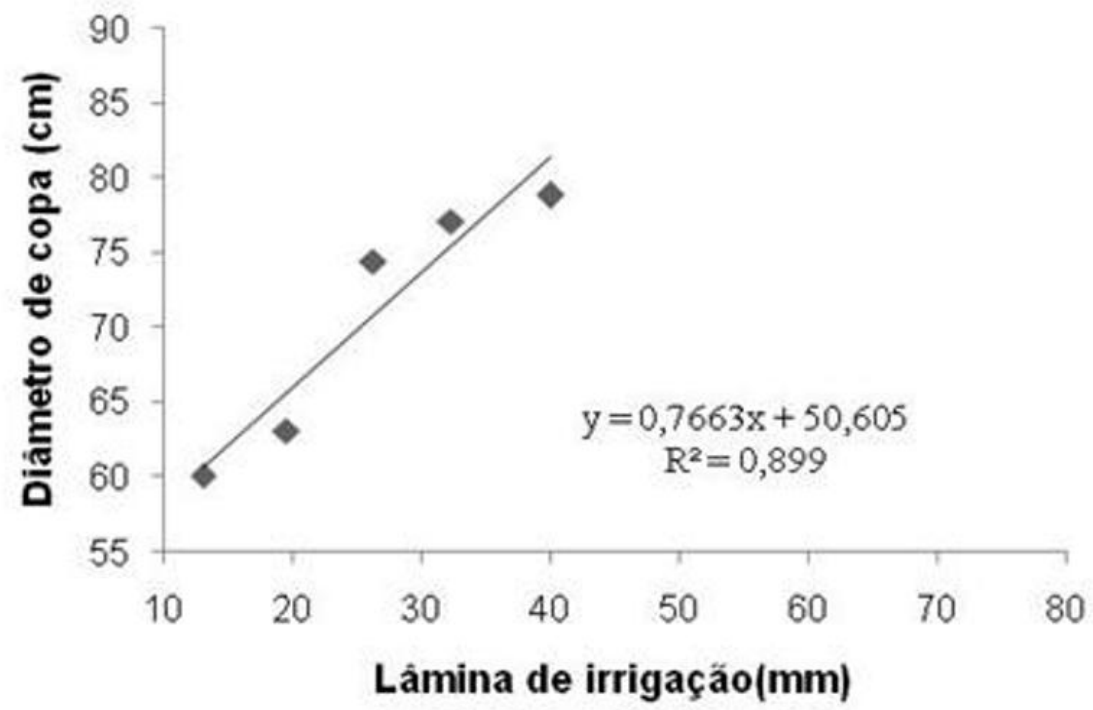

FIGURA 6. Variação do diâmetro de copa de plantas de noni submetidas a diferentes lâminas de irrigação aplicadas por gotejamento até 227 DAT. Trairi-CE, 2009.

de noni foi influenciado tanto pelos sistemas de irrigação, quanto pelas lâminas de água aplicadas, principalmente no final da estação seca. A aplicação da lâmina de irrigação equivalente a 100\% da ETo, utilizando o sistema de irrigação por microaspersão, proporcionou maiores ganhos de diâmetro do coleto, altura da planta, e diâmetro de copa do noni.

\section{AGRADECIMENTOS}

Os autores agradecem ao Banco do Nordeste do Brasil - BNB (FUNDECI) pelo financiamento da pesquisa.

\section{REFERÊNCIA}

ALVES, M. E. B. et al. Crescimento do cafeeiro sob diferentes lâminas de irrigação e fertirrigação. Revista Brasileira de Engenharia Agrícola e Ambiental, v. 4, n. 2, p. 219-225, 2000.

ARANTES, K. R. et al. Desenvolvimento do Cafeeiro(CoffeaarabicaL.) Podado sob Irrigação. Revista de Ciências Agro-Ambientais, v. 4, n. 1, p. 75-66, 2006.

CABRAL, R.C. Evapotranspiração de referência de Hargreaves (1974) corrigida pelo método de Penman-Monteith/FAO (1991) para o Estado do Ceará. 2000. 83 p. Dissertação (Mestrado em
Irrigação e Drenagem)-Departamento de Engenharia Agrícola - Universidade Federal do Ceará. Fortaleza. LÜBECK, W.; HANNES, H. Noniel valioso tesoro de los mares delsur.Editorial EDAF S. A. Madrid, Espana, 2001, 173 p.

KELLER, J.; KARMELI, D. Trickle irrigation design. Glendora: Rain BirdSprinkler Manufacturing, 1975. $133 \mathrm{p}$.

McCLATHEY, W. From Polynesian Healers to Health Food Stores: Changing Perspectives of Morinda citrifolia (Rubiaceae). IntegrativeCancerTherapies, v. 1, n. 2, p. 110-120, 2002.

REIS, M. G. F; REIS, G. G; REGAZZI, A. J; LELES, P. S.S. Crescimento e forma do fuste de mudas de jacarandáda-bahia (Dalbergianigra Fr. Allem.), sob diferentes níveis de sombreamento e tempo de cobertura. RevistaÁrvore, v. 15, n. 1, p. 23-24, 1991.

ROSS, I. A. Medical Plants of the World.Chemical Constituents, Traditional and Modern Medical Uses. New Jersey: Humana Press, 2 ed., 2001. 242 p.

TUROLLA, M. S. R.; NASCIMENTO, E. S. Informações toxicológicas de alguns

fitoterápicos utilizados no Brasil. Revista Brasileira de Ciências Farmacêuticas, v. 42, n. 2, 17 p. 2006.

WANG, M. Y; WEST, .B. J; JENSEN, C. J; NOWICKI, D.; SU, C.; PALU, A. K. Morindacitrifolia (Noni): A literature review and recentadvancesin Noni research. ActaPharmacologica Sin, v. 23, p.11271141, 2002. 